\title{
MODIFICATION OF BORON DOPED DIAMOND ELECTRODES WITH GLUCOSE OXIDASE, CHARACTERIZATION BY ELECTROCHEMICAL TECHNIQUES
}

\author{
RODRIGO DEL RÍO ${ }^{\prime *}$, FRANCISCO ARMIJO ${ }^{\prime}$, RICARDO SCHREBLER ${ }^{2}$, GABRIELA DEL CANTO ${ }^{\prime}$, \\ CLAUDIA VERGARA ${ }^{1}$, CESAR GUTIERREZ ${ }^{1}$
}

\author{
${ }^{1}$ Facultad de Química, Pontifícia Universidad Católica de Chile, Avda Vicuña Mackenna 4860, Macul, Santiago Chile \\ ${ }^{2}$ Instituto de Química, Facultad de Ciencias Básicas y Matemáticas, Pontifícia Universidad Católica de Valparaíso, Avda. Brasil 2850, Valparaíso, Chile.
}

(Received: September 15, 2010 - Accepted: March 8, 2011)

\begin{abstract}
In this work, we report the effect of the direct successive modifications with Glucose oxidase onto boron doped diamond electrode (BDD). The modification due to the enzyme adsorption, on the potentiodynamic response of the electrode, was evaluated using $\mathrm{Fe}(\mathrm{CN})_{6}^{4-3-}$ red-ox couple on the electrolyte and the $\Delta$ Ep variations were related with the number of modifications. Contact angle measurements and the electrochemical impedance spectra were also used to characterized the modifications and they showed variations in the same way that the potentiodynamic data.
\end{abstract}

Keywords: Boron Doped Diamond, Electrochemical Impedance Spectroscopy, Enzyme Adsorption, Glucose Oxidase, Cyclic Voltammetry.

\section{INTRODUCTION}

The electrochemistry of doped diamond electrodes was first studied by Pleskov' ${ }^{1}$, and since, Boron doped diamond electrodes (BDD) have been extensively studied, from a fundamental point of $v_{i e w^{2-5}}$, as well as that of applications ${ }^{6-8}$. Its more interesting feature is the high overpotential for both, hydrogen and oxygen evolution ${ }^{9-10}$. The physical, chemical and electronics properties affect the electrochemical behavior of BDD electrodes and these properties are dependent on quantity and kind of dopant, impurities and surface termination. The surface termination is usually generated by electrochemical methods, using the water reduction or oxidation, to produce $\mathrm{H}$-termination or O-termination respectively ${ }^{11-12}$. Granger and Swain showed that the reversibility of certain redox couples is dependent on the surface termination of $\mathrm{BDD}^{13}$. Suffredini et. al. reported that $\mathrm{Fe}(\mathrm{CN})_{6}^{4-3-3}$ shows a reversible response on cathodically pre-treated BDD electrode and quasi reversible response if the electrode was anodically treated ${ }^{14}$, or the cathodically pre-treated BDD electrode, lose the $\mathrm{Fe}(\mathrm{CN})_{6}^{4-/ 3-}$ reversibility with time ${ }^{5}$.

The BDD was especially well studied for electroanalytical applications due to the special properties of this material. Determinations of chlorophenols ${ }^{15}$, cysteine $^{16}$, caffeine ${ }^{17}$, and others were reported. In most of the cases unmodified electrodes have been used, but nanoparticles modified electrodes also have been studied ${ }^{18}$.

$\mathrm{A} \mathrm{Ru}[\mathrm{bpy}]_{3}{ }^{3+}$ modified oxidized BDD electrode has been prepared by $\mathrm{Wu}$ et al. ${ }^{19}$, in order to detect a catechin autoxidation intermediate. Notsu et al..$^{20}$ have reported a tyrosinase modified oxidized BDD electrode for determining phenols. Fortin et. al. ${ }^{21}$ study the oxidation reactions of the nucleosides 2 -deoxyguanosine and 2'-deoxyadenosine on an oxygenated boron-doped diamond electrode were discussed. However, to date there have been few reports concerning third-generation enzyme biosensors based on the oxidized BDD electrode. Wu et. al. reported on a third-generation glucose biosensor that has Glucose oxidase (GOD) immobilized on the surface of an oxidized BDD electrode by modification with a mixture of Bovine Serum Albumine (BSA) and glutaraldehyde and works without a mediator ${ }^{22}$. In this work, we report the direct modification of a BDD electrode and its electrochemical characterization, in order to design a third generation biosensor.

\section{EXPERIMENTAL}

A BDD electrode from adamant Technologies was used as working electrode (p-doped, polycrystalline, $500 \mathrm{ppm}$ boron doped). Previous to use, the electrode was washed with acetone, ethanol and water bi-distillated. A one compartment electrochemical cell was used with a saturated calomel electrode as reference electrode and a platinum coil as counter-electrode. The electrolyte used was $\mathrm{K}_{4} \mathrm{Fe}(\mathrm{CN})_{6} 10 \mathrm{mM} \mathrm{y} \mathrm{K}_{3} \mathrm{Fe}(\mathrm{CN})_{6} 10 \mathrm{mM}$. The BDD electrode was pretreated applying an $( \pm) 0.16 \mathrm{~mA}^{3}$ constant current, until reach $80 \mathrm{C}$ of electrical charge in $\mathrm{H}_{2} \mathrm{SO}_{4} 0.5 \mathrm{M}$, to obtain the anodically or cathodically pretreated working electrode.
The enzyme adsorption on the electrode was performed from a $4,0 \mathrm{UE} / \mathrm{mL}$ GOD type II from aspergillus niger (Sigma) aqueous solution. $20 \mu \mathrm{L}$ of this solution was dipped on the electrode surface for $20 \mathrm{~min}$ and then washed away with distilled water. Successive modifications were performed repeating the procedure after the corresponding electrochemical characterization.

Calibration curve was performed fixing the electrode potential at $1.2 \mathrm{~V}$ and the current was registered after addition of $100 \mathrm{~mL}$ of glucose $1 \mathrm{M}$ in $30 \mathrm{~mL}$ of a buffer phosphate solution (PBS) pH 7.4 mechanically stirred.

The BDD characterization was done by cyclic voltammetry at different scan rates. Besides, electrochemical impedance spectroscopy (EIS) was performed at open circuit potential between $10 \mathrm{mHz}$ to $10 \mathrm{kHz}$ with an $10 \mathrm{mV}$ ac perturbation by means of a potentiostat $\mathrm{CH} 604 \mathrm{c}(\mathrm{CH}$ instruments) and an Ecochemie PGSTAT30 system. All solutions were kept at room temperature (approximately $23^{\circ} \mathrm{C}$ ) and purged with argon.

A Dataphysics OCA 20 device with a conventional goniometer and high performance video camera, controlled by SCA20 software, was used to measure the optical contact angle exposing a clean pretreated diamond surface to a $10 \mathrm{~mL}$ water drop measuring the angle between the drop and surface, the same procedure were performed to the modified electrodes.

\section{RESULTS AND DISCUSSION}

\section{Effect of the pre-treatment on BDD electrode response}

Figure $1 \mathrm{~A}$, shows the potentiodynamic response of an anodically (solid line) and cathodically (dashed line) pre treated BDD electrodes in the presence of the red-ox couple $\mathrm{Fe}(\mathrm{CN})_{6}^{3-44}$. In this figure, for anodically pretreated electrode, two current peaks at $0.53 \mathrm{~V}$, the anodic one and at $-0.18 \mathrm{~V}$, the cathodic one, are observed. The $\Delta \mathrm{Ep}=0.71 \mathrm{~V}$ on the potentiodynamic response of this red-ox couple, indicates that the red-ox couple shows a high irreversibility on this substrate. This behavior was well studied ${ }^{5}$ and it is due to the presence of oxygen terminated active sites. These sites could be suitable to the adsorption of different species, such as the glucose oxidase used in this study. On the other hand, the BDD electrode used has a low boron dopage, this characteristic is other reason to observe a high $\Delta$ Ep value ${ }^{5}$. The $I_{p p}$ is dependent on the square root of the scan rate (not shown), this linear relationships is typical of reversible diffusion controlled reaction, such as the showed by the system $\mathrm{Fe}(\mathrm{CN})_{6}^{3-14}$. Figure $1 \mathrm{~B}$, shows the Nyquist diagram obtained at the open circuit potential for both electrodes, anodically (solid circle) and the cathodically (open triangle) pre-treated electrodes. In this figure is possible to observe the typical response of the system $\mathrm{Fe}(\mathrm{CN})_{6}^{3-4-5}$, with a semi circle and after that a $45^{\circ}$ line due to a Warburg element for both electrodes. From the semi circle, a $210 \mathrm{Ohm} \mathrm{R} \mathrm{R}_{\mathrm{ct}}$ can be obtained for the anodically pre-treated electrode 

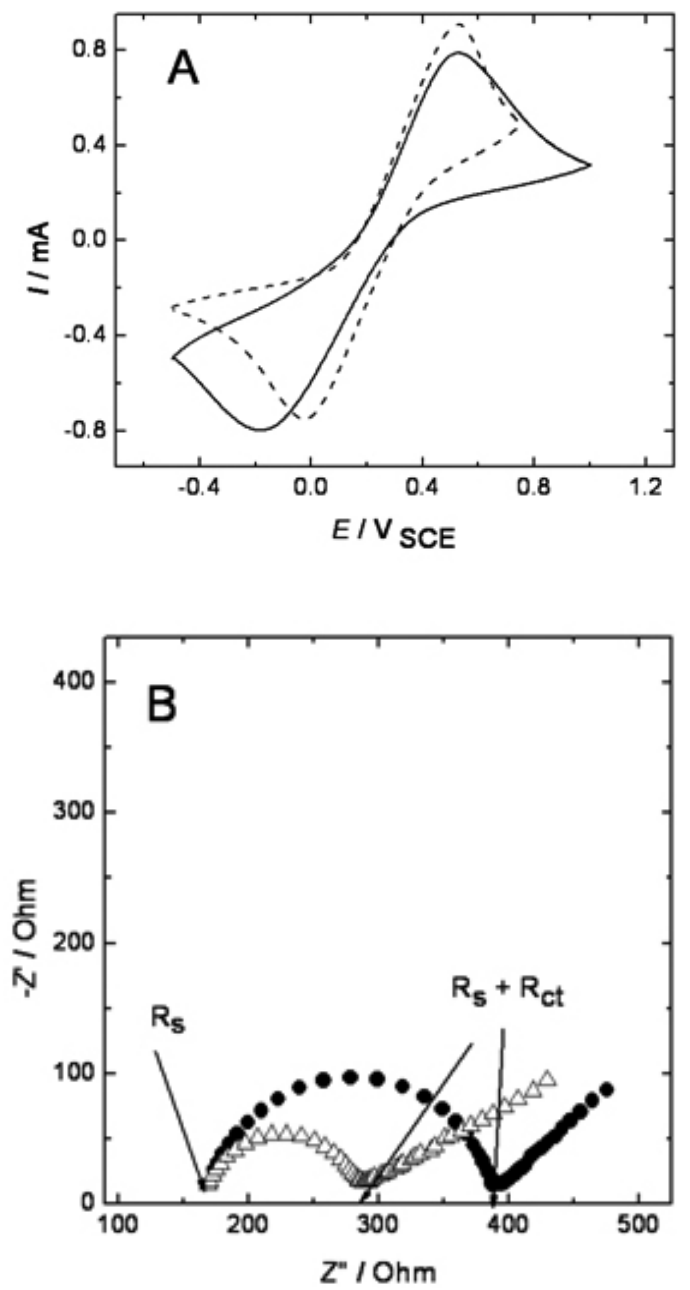

Figure 1 A) Potentiodynamic profile of anodically (solid line) and cathodically (dashed line) pretreated BDD electrodes in $10 \mathrm{mM} \mathrm{K}_{4} \mathrm{Fe}(\mathrm{CN})_{6}, 10$ $\mathrm{mM} \mathrm{K}, \mathrm{Fe}(\mathrm{CN})_{6}$ at $0,1 \mathrm{~V} \mathrm{~s}^{-1}$. B) Nyquist diagram for anodically (solid circle) and cathodically (open triangle) pretreated BDD electrodes at the open circuit potential in the same electrolite

Figure $1 \mathrm{~A}$, also shows the potentiodynamic response of a cathodically pre treated BDD electrode in the presence of the red-ox couple $\mathrm{Fe}(\mathrm{CN})^{3-1 / 4}$. In this figure two current peaks at $0.53 \mathrm{~V}$, the anodic one and at $-0.03 \mathrm{~V}$, the cathodic one, are observed. The $\Delta \mathrm{Ep}=0.56 \mathrm{~V}$ on the potentiodynamic response of this red-ox couple, indicates that the red-ox couple shows a lower irreversibility on this substrate compares with the anodic pretreatment. Such as was reported, the red-ox couple $\mathrm{Fe}(\mathrm{CN})_{6}^{3-4-}$ is very reversible in $\mathrm{BDD}$ electrodes cathodic pretreated, but the reversibility is a function of the boron content, and in this case the low dopage is the responsible of the irreversibility observed ${ }^{5}$. Again, the $I_{p a}$ values are dependent with the square root of the scan rate. Figure 1 B, shows the Nyquist diagram obtained at the open circuit potential. In this figure is possible to observe a semi circle and after that a $45^{\circ}$ line due to a Warburg element. From the semi circle, a $110 \mathrm{Ohm} \mathrm{R}$ can be obtained. From the DEp and Rct values is possible to confirm that, on the cathodically pre-treated BDD electrode, the reactions studied are more reversible than on the anodically pretreated.

\section{Enzyme Adsorption}

The enzyme adsorption was performed directly on the electrode surface, without any reagents to assure the adsorption. Figure $2 \mathrm{~A}$, shows the variation on the potentiodynamic profile, before and after modification. The figure shows a slightly change in the peak potential, increasing the $\Delta \mathrm{Ep}$ from 0.71 to 0.79 , this effect is due to the lowering of the active sites by the modification. In the same way, the nyquist diagram shows in the figure $2 \mathrm{~B}$ shows a variation on the
$\mathrm{R}_{\mathrm{ct}}$ from 210 to $250 \mathrm{Ohm}$. This result indicates that the modification process could be observed by means of electrochemical measurements, but the slight variations observed suggest evaluate the cathodic pretreatment.
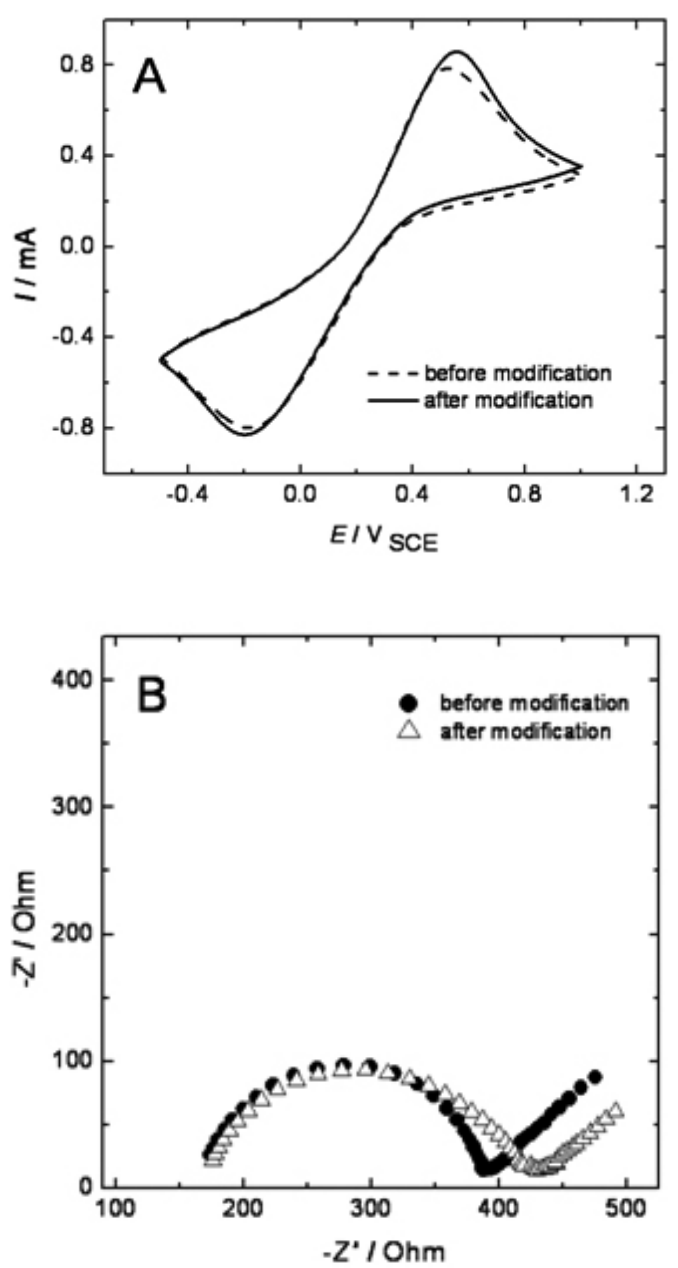

Figure 2 A) Potentiodynamic profile of BDD electrode anodically pretreated in $10 \mathrm{mM} \mathrm{K}, \mathrm{Fe}(\mathrm{CN}), 10 \mathrm{mM} \mathrm{K}, \mathrm{Fe}(\mathrm{CN})$ at $0,1 \mathrm{~V} \mathrm{~s}^{-1}$, before (dashed line) and after (solid line) modification with GOD. B) Nyquist diagram for the same electrode before (solid circle) and after (open triangle) modification with GOD, EIS spectra registered at the open circuit potential

The same procedure was used to study a cathodically pretreated electrode and the results are shows in Figure 3. First, the potentiodynamic response in the Figure $3 \mathrm{~A}$, shows that the $\Delta \mathrm{Ep}$ change from $0.57 \mathrm{~V}$ to $0.71 \mathrm{~V}$ as the results of the enzyme adsorption. This greater change suggests the study of successive adsorption on the same electrode and the $\Delta \mathrm{Ep}$ continues increasing indicating that the enzyme continues the adsorption process. From the EIS spectra showed in Figure $3 \mathrm{~B}$, the $\mathrm{R}$ values were obtained and they increase in the same way that the potentiodynamic data. The response of the red-ox couple in this electrode (cathodically pretreated) is more reversible, so that could be the reason of the major variations observed with the number of the modification processes (repeating the same modification procedure). Moreover, the EIS data show variations in the $\mathrm{R}_{\mathrm{ct}}$ value from $126 \mathrm{ohm}$ to 200 $\mathrm{ohm}$ with the first modifications and this value continues increasing with the number of modifications. Finally, from this figure is possible to conclude that the cathodically pretreated electrode is more suitable in order to study the modification of the electrode by adsorption of this enzyme, the reversibility of the red-ox couple in this electrode allows a better characterization of the modification process and the modification are stable because between the modification processes, the electrode was electrochemically study and toughly washed with water. 

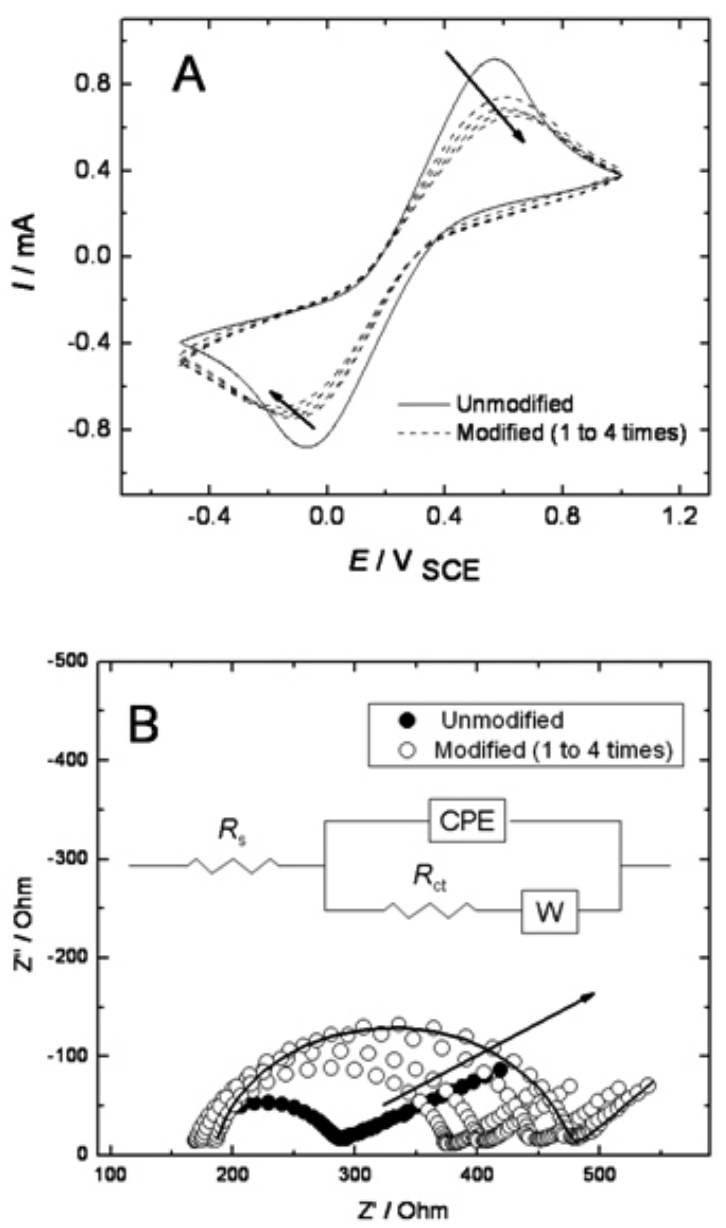

Figure 3 A) Potentiodynamic profile of BDD electrode cathodically pretreated in $10 \mathrm{mM} \mathrm{K}, \mathrm{Fe}(\mathrm{CN})_{6}, 10 \mathrm{mM} \mathrm{K}_{3} \mathrm{Fe}(\mathrm{CN})_{6}$ at $0,1 \mathrm{~V} \mathrm{~s}^{-1}$, before (solid line) and after (dashed line) successive modifications with GOD. B) Nyquist diagram for the same electrode before (solid circle) and after (open circle) successive modifications with GOD, EIS spectra registered at the open circuit potential

The EIS data were simulated using the typical equivalent circuit used for the couple $\mathrm{Fe}(\mathrm{CN})_{6}^{3-14}$. The double layer capacitance was simulated using a constant phase element and the a values change from 0.9 for the unmodified electrode to 0.85 for the modified ones. This parameter is very sensitive to the surface characteristic and this change is due to the presence of the enzyme on the electrode surface.

The difference in the $\Delta \mathrm{Ep}$ and in the $\mathrm{R}_{\mathrm{ct}}$ values were related with the number of modification. These relationships are shown in figure $4 \mathrm{~A}$. In this figure, is possible to observe that both values follow the same trends, like as an adsorption isotherm. So, is possible to conclude that the electrochemical measurements allow us to evaluate the modification of the BDD electrode.

To confirm that the electrochemical data are representing the modification of the electrode, contact angle measurements were performed to the unmodified electrode and after the respective successive modifications. The unmodified electrode has a contact angle with the water drop of $27.9^{\circ}$, indicating an hydrofobic surface; the pretreatment applied to the electrode provoke an H-terminated surface, which is responsible of the hydrophobic character of the surface. After the modification the contact angle increase to $57.5^{\circ}$ as a consequence of the modification, successive modifications increase the contact angle until to $73.1^{\circ}$. This variation is reflecting the modification of the electrode surface and when is representing together the DEp values in Figure 4 B, shows the same variation of the electrochemical data. So, physical and electrochemical measurements are representing the modification of the electrode surface by the enzyme like an isotherm.

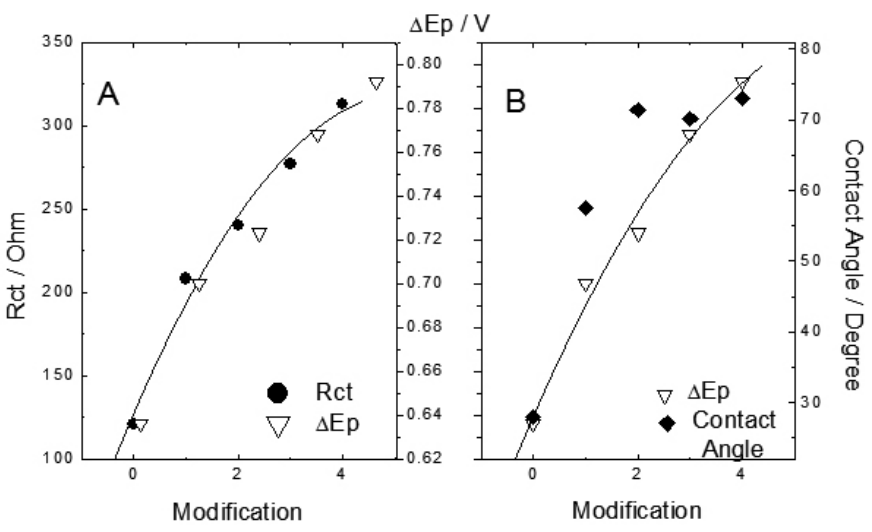

Figure 4 A) $\mathrm{R}_{c t}$ (close circle) and DEp (open triangle) vs modification number plot for cathodically pretreated BDD electrode. B) Contact Angle (close diamond) and DEp (open triangle) vs Modification number plots for cathodically pretreated BDD electrode.

So, as, the physical and electrochemical data shows the modification of the electrode, a cyclic voltammetry experience was performed in glucose containing solution to confirm that the enzyme activity remains. Figure $5 \mathrm{~A}$ shows the calibration curve obtained by measuring the potentiostatic response of the modified (4 modifications) BDD electrode in PBS buffer solution after additions of $100 \mu \mathrm{L}$ of $1 \mathrm{M}$ glucose solution, the inset shows the response of the electrode after each addition. From the calibration plot a detection limit of $14 \mathrm{mM}$ was obtained $(3 \mathrm{SD} / \mathrm{m}, \mathrm{SD}=$ standard deviation, $\mathrm{m}=$ slope $)$, this value is close to the detection limit found with aniline copolymers ${ }^{23}$. In figure $5 \mathrm{~B}$ the potentiodynamic profile of the unmodified and modified BDD electrodes in a phosphate saline solution $\mathrm{pH} 7.4$ containing $10 \mathrm{mM}$ of glucose were shown. In this figure an anodic wave is observed starting in $0.6 \mathrm{~V}$ compared to the unmodified electrode, this current wave is due to the glucose oxidation and indicates that at potentials more positive than $0.6 \mathrm{~V}$ the glucose oxidation takes place and allows to design a glucose biosensor by direct modification of cathodically pretreated BDD electrode. Studies on the application of this electrode to the glucose oxidation are in course.

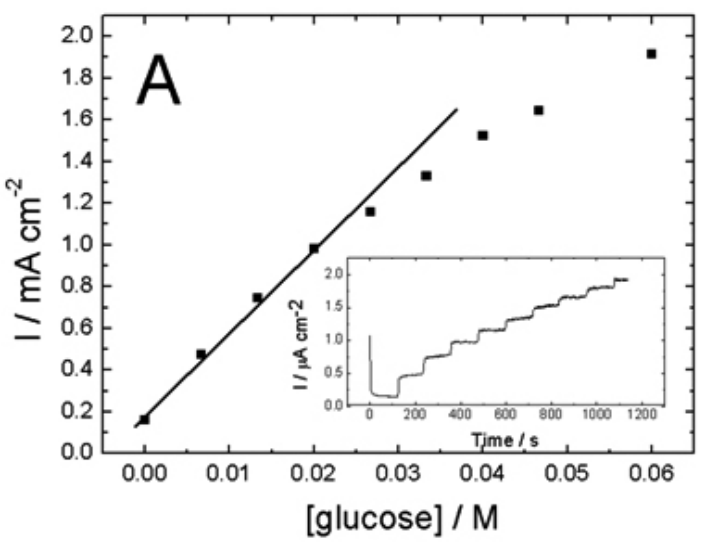




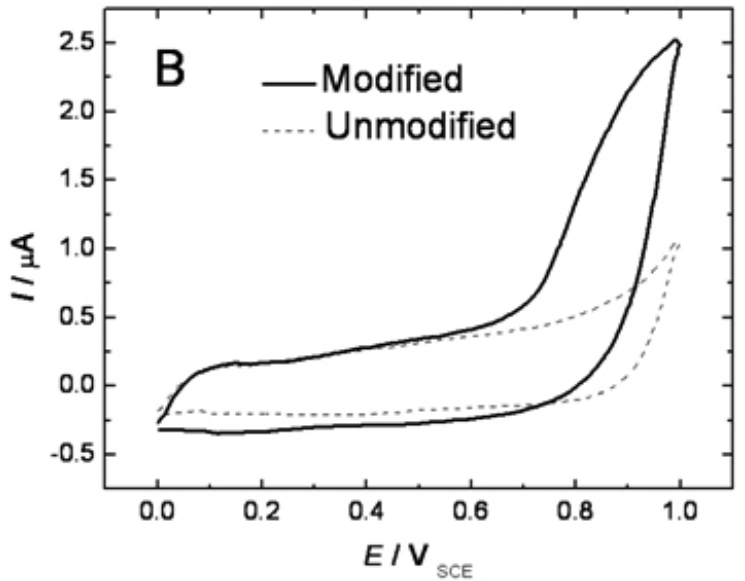

Figure 5 A) calibration plot of glucose using modified BDD electrode, inset shows the potentiostatic response of modified BDD electrode in PBS solution at $1.2 \mathrm{~V}$ after addition of different quantities of $1 \mathrm{M}$ glucose solution) B) Potentiodynamic profile of cathodically pretreated BDD electrode in PBS buffer solution $\mathrm{pH} 7.4$ at $0.1 \mathrm{Vs}^{-1}$, in the presence (solid line) and absence (dashed line) of $10 \mathrm{mM}$ glucose.

\section{CONCLUSIONS}

From this work is possible to conclude that a BDD electrode cathodically pretreated electrode was directly modified with GOD. The contact angle measurements, $\mathrm{DEp}$ and $\mathrm{R}_{\mathrm{ct}}$ are parameters adequate to study the adsorption phenomena in BDD electrode and the results presented indicated that this type of methodology could be applied to design a biosensor based in BDD electrode.

\section{REFERENCES}

1.- Y.V. Pleskov, A.Y. Sakharova, M.D. Krotova, L.L. Builov and B.V. Spitsyn, J. Electroanal. Chem. 228, 19, (1987)

2.- R. Tenne, C. Lévy-Clément, Isr. J. Chem. 12, 1940, (2003)

3.- Y.V. Pleskov, Russ. J. Electrochem. 38, 1411, (2002)

4.- $\quad$ G.M. Swain, A.B. Anderson, J.C. Angus MRS Bull. 23, 56, (1998)

5.- G. R. Salazar-Banda, L.S. Andrade, P.A.P. Nascente, P.S. Pizani, R.C. Rocha-Filho, L.A. Avaca, Electrochim. Acta 51, 4612, (2006)

6.- W. Haenni, P. Rychen, M. fryda and C. Comninellis in Thin-film diamond part B, Ch. Nebel ed. Academic Press, Semiconductors and Semimetals series, Elsevier, 2004, p.149.

7.- $\quad$ X. Zhao, Y. Hou, H. Liu, Z. Qiang, J. Qu, Electrochim. Acta 54, 4172, (2009)

8.- $\quad$ W.-Y. Su, S.-H. Cheng, Electroanalysis, 22, 707, (2010)

9.- M. Fryda, L. Schäfer, I. Tröster, Recent Res. Devel. Electrochem. 4, 85, (2000)

10.- M. Fryda, T. Matthee, S. Mulcahy, A. Hampel, L. Schäfer, I. Tröster, Diamond Relat. Mater. 12, 1950, (2003)

11.- C.H. Goeting, F. Marken, A. Gutiérrez-Sosa, R.G. Compton, J.S. Foord, Diamond Relat. Mater. 9, 390, (2000)

12.- S. Ferro, A. De Battisti, Electrochim. Acta, 47, 1641, (2002)

13.- M.C. Granger, G.M. Swain, J. Electrochem. Soc. 146, 4551, (1999)

14.- H.B. Suffredini, V.A. Pedrosa, L. Codognoto, S.A.S. Machado, R.C. Rocha-Filho, L.A. Avaca, Electrochim. Acta, 49, 4021, (2004)

15.- L. Codognoto, S.A.S. Machado, L.A. Avaca, Diamond, Relat. Mater. 11, $262,(2002)$

16.- N. Spataru, B.V. Sarada, E. Popa, D.A. Tryk, A. Fujishima, Anal. Chem. 73, 514, (2001)

17.- N. Sparatu, B.V. Sarada, D.A. Tryk, A. Fujishima, Electroanalysis, 14, $721,(2002)$

18.- M. Limat, B El Roustoma, H Jotterand, G Fóti, C. Comninellis, Electrochim. Acta 54, 2410, (2009)

19.- J. Wu, H. Wang, L. Fu, Z. Chen, J.H. Jiang, G. Shen, R. Yu, Talanta 65, $511,(2005)$

20.- H. Notsu, T. Tatsuma, A Fujishima, J. Electroanal. Chem. 523, 86, (2002)

21.- E. Fortin, E. Vieil, P. Mailley, S. Szunerits, T. Livache, Anal. Chem. 79, $3741,(2007)$

22.- J. Wu. Y. Qu, Anal. Bioanal. Chem. 385, 1330, (2006)

23.- C.O. Sanchez, A. Isla, C. Busto, F. Díaz, N. Gatica, J. Chil. Chem. Soc. $\mathbf{5 5}, 233,(2010)$

\section{ACKNOWLEDGEMENTS}

Financial Support of FONDECYT-Chile, Grant 1070267 and VRAIDPUC are gratefully.

This work is dedicated to Dr. Mario Bodini Cruz-Carrera on this retirement. 